DOI: 10.20472/IAC.2019.046.007

\author{
ARUNABHA CHANDA \\ JADAVPUR UNIVERSITY, India
}

\title{
TECHNOLOGICAL IMPLICATIONS OF FLUID FLOW AND HEAT TRANSFER IN MICROCHANNELS
}

\begin{abstract}
:
Heat transfer and fluid flow in microchannels have been topics of intense research in the past decade. A critical review of the current state of research is presented with a focus on the future research needs. On basis of six topics related to transport phenomena in microchannels: single-phase gas flow, enhancement in single-phase liquid flow and flow boiling, flow boiling instability, condensation, electronics cooling, and microscale heat exchangers. It has also been demonstrated that the shear work due to the slipping fluid increases the effect of viscous heating on heat transfer. On the other hand, very few experiments support the theoretical models and a significant effort should be made in this direction, especially for measurement of temperature fields within the gas in microchannels, implementing promising recent techniques such as molecular tagging thermometry (MTT). The single-phase liquid flow in microchannels has been established to behave similar to the macroscale flows. The current need is in the area of further enhancing the performance. Progress on implementation of flow boiling in microchannels is facing challenges due to its lower heat transfer coefficients and critical heat flux (CHF) limits. With this, condensation heat transfer models can progress from primarily annular flow based models with some adjustments using dimensionless parameters to those that can directly account for transport in intermittent and other flows, and the varying influences of tube shape, surface tension and fluid property differences over much larger ranges than currently possible. Electronics cooling continues to be the main driver for improving thermal transport processes in microchannels, while efforts are warranted to develop high performance heat exchangers with microscale passages. Specific areas related to enhancement, novel configurations, nanostructures and practical implementation will be handled in the research with appropriate numerical techniques. The conditions for micro channel flow will be sought from the present numerical analysis.
\end{abstract}

\section{Keywords:}

Microchannels, critical heat flux, microscale cooling 